\title{
Possible Role of Increased Sodium Gradient on Intradialytic Hypertension Phenomenon
}

\author{
MOHAMMAD A. SOBH, M.D.; AHMAD M.A. OBIED ALLAH, M.D. and YASSER A. FYSAL, M.Sc. \\ The Department of Internal Medicine, Faculty of Medicine, Assiut University, Assiut, Egypt
}

\begin{abstract}
Background: Intradialytic hypertension is poorly understood neglected complication of hemodialysis. Better understanding of the pathogenesis of this phenomenon will lead to better management of this complication.
\end{abstract}

Aim of Work: To detect the frequency of intradialytic hypertension among Hemodialysis patients in Assiut University dialysis unit and the role of increased sodium gradient on this phenomenon.

Patients and Methods: A cross-sectional study included 200 hemodialysis patients in Assiut University Dialysis Unit was conducted between January 2017 and Mars 2017. Intradialytic hypertension was defined as an increase in systolic $\mathrm{BP}>10 \mathrm{mmHg}$ from pre to post dialysis. Patients were subjected to detailed history and careful examination. Pre and post hemodialysis blood pressure were measured. Pre dialysis plasma sodium was measured and Sodium gradient was calculated as: Dialysate sodium (dNa)-pre hemodialysis plasma sodium $(\mathrm{pNa})$.

Statistical Analysis: Statistical analysis of data was performed using SPSS version 23. To compare between patients we use student's $t$-test for unpaired normally distributed data Mann-Whitney test for medians, and ${ }_{\times 2}$ test for categorical data.

Results: 60 patients (30\%) had intradialytic hypertension. The intradialytic hypertensive patients had lower predialytic plasma $\mathrm{Na}$ and higher $\mathrm{Na}$ gradient compared to the control group. Mean predialytic $\mathrm{Na}$ sodium and $\mathrm{Na}$ gradient in the case group were 132.66 and 7.33 respectively, while 137 and 2.7 in the control group respectively.

Conclusion: The frequency intradialytic hypertension in our center was $30 \%$. Intradialytic hypertension is strongly associated with increased sodium gradient.

Key Words: Dialysis sodium gradient, Intradialytic hypertension, Hemodialysis.

Correspondence to: Dr. Mohammad A. Sobh,

The Department of Internal Medicine, Faculty of Medicine, Assiut University, Assiut, Egypt

\section{Introduction}

HEMODIALYSIS is one of the modalities of renal replacement therapy for End Stage Renal Disease (ESRD) patients. The most common expected response to a Hemodialysis treatment (HD) is a decrease in systolic Blood Pressure (BP) of about $10-15 \mathrm{~mm} \mathrm{Hg}$ with BP reduction more steeply during the first hour and then decreasing more slowly for the remaining duration of the session [1]. However, a notable subgroup demonstrating increases in BP during the treatment. This increase in BP during hemodialysis, termed Intradialytic Hypertension (IDH) [2] . There are multiple definitions for IDH, but, to date, there is no standard definition. An increase in Systolic BP (SBP) $>10$ $\mathrm{mmHg}$ from pre to post dialysis is one of the most popular definitions [3]. Prevalence may differ from study to another. Observation studies in the 1990s demonstrated that hypertension during dialysis occurs in $\approx 5 \%$ to $15 \%$ of patients [4]. In another study it reached $28.4 \%$ [5]. In a cohort of more than 100,000 hemodialysis patients followed for more than 5 years, a mean systolic BP reduction of $14 \mathrm{~mm} \mathrm{Hg}$ represented the group with the best survival [6]. The highest mortality occurred in patients with either any rise in systolic BP or a $30 \mathrm{mmHg}$ reduction in systolic BP [6]. This impor-

\footnotetext{
Abbreviation:

BMI : Body Mass Index.

BP : Blood Pressure.

CCB : Calcium Channel Blocker.

$\mathrm{dNa}$ : Dialysate Sodium Concentration.

ESA : Erythropoietin-Stimulating Agents.

ESRD : eNd Stage Renal Disease.

HD : Hemodialysis.

IDH : Intradialytic Hypertension.

$\mathrm{NaG}$ : Sodium Gradient.

JVP : Jugular Venous Pressure.

$\mathrm{pNa}$ : Pre Dialysis Plasma Sodium.
} 
tant study demonstrated the risk associated with intradialytic hypertension and the need to identify the pathogenesis of this phenomenon. The pathogenesis of intradialytic hypertension is complex and not yet fully understood. Several factors have been proposed to be involved in the pathogenesis of this phenomenon [7]. These factors are summarized in the Fig. (1) below.

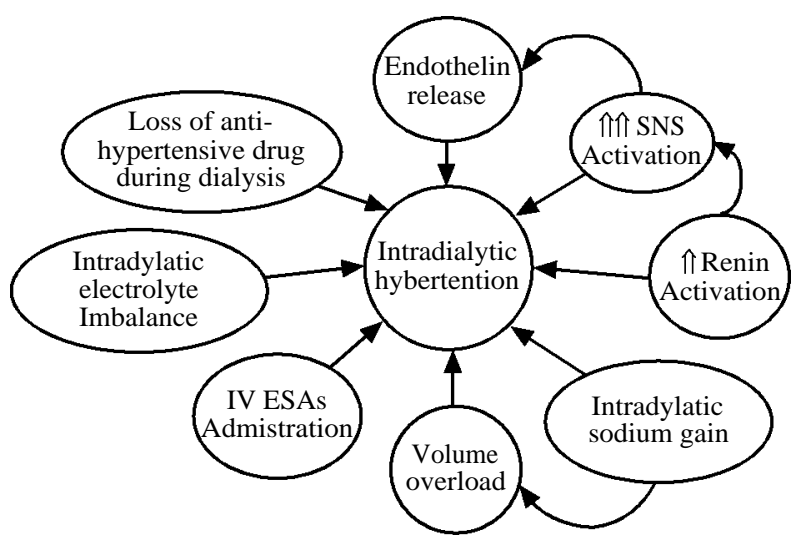

Fig. (1): Pathogenesis of intradialytic hypertension.

SNS: Sympathetic Nervous System.

I. V. : Intravenous.

ESA: Indicates Erythropoietic-Stimulating Agent.

Intradialytic hypertension is neglected poorly understood complication of HD. Early identification and management of this complication will decrease the cardiovascular risks. Better identification of risk factors of IDH will lead to better management.

Aim of work: To detect the frequency of intradialytic hypertension among Hemodialysis patients in Assiut university dialysis unit and the role of increased sodium gradient on this phenomenon.

\section{Patients and Methods}

It is cross sectional study. The study included all ESRD patients in Assiut University Dialysis Unit (213patients). Patients excluded from this study were patients with advanced heart failure, advanced liver cirrhosis, active sever infection, advanced hyperglycemia and advanced malignancy.

Subjects: 200 ESRD patients met inclusion and exclusion criteria. We used the definition (an increase in Systolic BP (SBP) $>10 \mathrm{mmHg}$ from pre to post dialysis) to determine the intradialytic hypertensive patients from those without. After determination of patients with IDH (the case groups), 60 age and sex matched ESRD patients, whose blood pressure decreased with ultrafiltration, were taken as control group. Hemodialysis were performed on Fresenius 4008 and Gambro AK 95S HD machines, 2-3 times a week with a duration of 3 to 4 hours per session the blood flow rates ranged between 200 to $300 \mathrm{ml} / \mathrm{min}$, and the dialysate flow from 500 to $600 \mathrm{ml} / \mathrm{min}$. The dialysate sodium concentration $(\mathrm{dNa})$ was $140 \mathrm{mmol} / \mathrm{L}$ for all patients. Detailed history from the patients was taken especially: Age (years), gender, duration of dialysis, number of dialysis session per week, duration of dialysis session, number and type of antihypertensive drugs. Careful examination especially (BP, pulse, Jugular Venous Pressure (JVP), chest examination, lower limb examination for edema) was done. Study duration was from January 2017 and Mars 2017. Informed oral consent was taken from the patients. The study protocol was approved by the Local Ethics Committee in Faculty of Medicine, Assiut University.

\section{Measurements:}

Pre- and Post-HD blood pressure were measured. These values were obtained by using a sphygmomanometer after the patient was at rest for $5 \mathrm{~min}$ in a supine or sitting position in mid-week dialysis in two successive weeks.

Weight, height were measured fore case and control group. Body Mass Index (BMI) was calculated as weight $/ \mathrm{height}^{2}\left(\mathrm{~kg} / \mathrm{m}^{2}\right)$.

Predialytic plasma Sodium concentration $(\mathrm{pNa})$ : A blood sample was collected before the midweek dialysis session and $\mathrm{pNa}$ was measured using $\mathrm{Di}$ estro 103 AP V3.The dNa concentration was determined using the online conductivity measurements on the Gambro AK 95S HD machines and Fresenius 4008 .

Sodium gradient was calculated as: dNa-preHD pNa.

\section{Statistical analysis of data:}

Statistical analysis of data was performed using SPSS Version 23, word processing data base and statistics programs. Continuous data were expressed as mean $\pm \mathrm{SD}$ or median and interquartile range. Comparisons between patients were performed using student's $t$-test for unpaired normally distributed data, Mann-Whitney test for medians, and $\chi^{2}$ test for categorical data.

\section{Results}

Our study included 200 patients; 60 patients $(30 \%)$ had intradialytic hypertension. 
The demographic and clinical data of the studiedpatients:

Table (1): Showing patient demographics involving the two groups collectively*.

\begin{tabular}{ll}
\hline Age in years & $45.40 \pm 13.977$ \\
Sex & 72 males, 48 females \\
Weight in $\mathrm{Kg}$ & $66.11 \pm 15.598$ \\
Height in cm & $162 \pm 8.6$ \\
Body mass index & $25 \pm 5.2$ \\
*: Data are expressed in mean \pm standard deviation, while sex as a \\
categorical data is expressed in counts.
\end{tabular}

Table (2): Comparison of different demographic data.

\begin{tabular}{|c|c|c|c|}
\hline & Case group & Control group & $p$-valu \\
\hline Age in years & $46.28(14.8)$ & $44.52(13.1)$ & 0.491 \\
\hline Number of males & 36 & 36 & 0.574 \\
\hline Weight in Kg & $64.88(15.466)$ & $67.34(15.76)$ & 0.390 \\
\hline Height in $\mathrm{cm}$ & $161.8 \pm 9$ & $162 \pm 8$ & 0.723 \\
\hline Body mass index & $24.7(5.3)$ & $25.5(5.2)$ & 0.452 \\
\hline Dialysis duration** & $5.75 \pm 4.16$ & $5.94 \pm 3.93$ & 0.794 \\
\hline
\end{tabular}

* : Data are expressed in mean (standard deviation), while sex as a categorical data is expressed in counts.

**: Duration of dialysis is expressed in year.

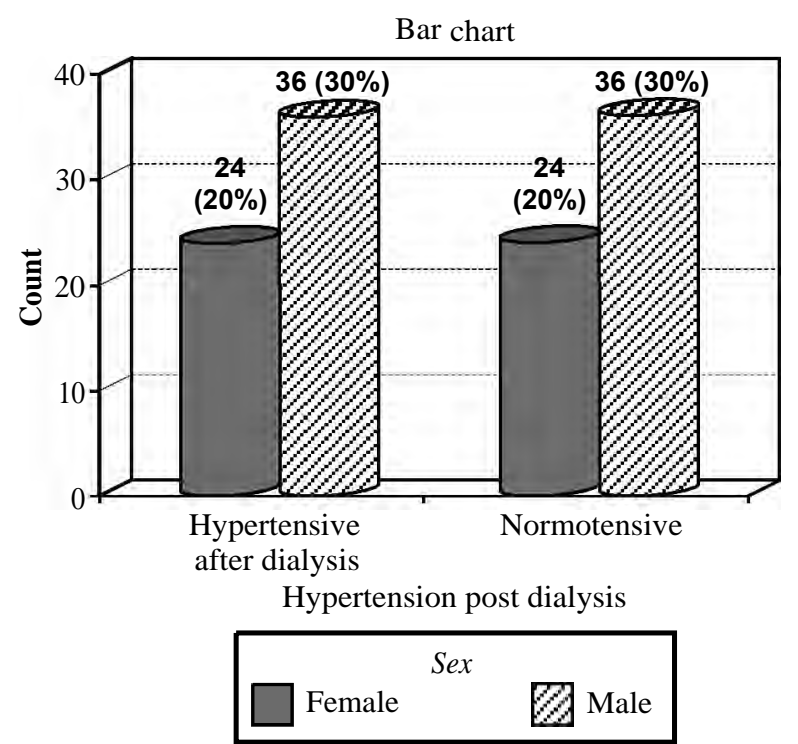

Fig. (2): Sex distribution of the patients in each group where the data was expressed in form of number and percentage.

\section{Predialyticplasma Sodium and sodium gradient:}

Mean Predialytic plasma sodium (pNa) and sodium gradient $(\mathrm{NaG})$ in the case group were 132.66 and 7.33 respectively, while 137 and 2.7 in the control group respectively. The IDH patients had lower predialytic plasma $\mathrm{Na}$ and higher $\mathrm{Na}$ gradient compared to the control group. There were statistically significant differences in Predialytic plasma $\mathrm{Na}$ and $\mathrm{Na}$ gradient between the two groups according to $t$-test with $p$-value 0.000 . Fig. (3) and (Table 3) show comparison of the mean and SD of pre-dialytic $\mathrm{Na}$ and $\mathrm{Na}$ gradient in each group using independent student $t$-test.

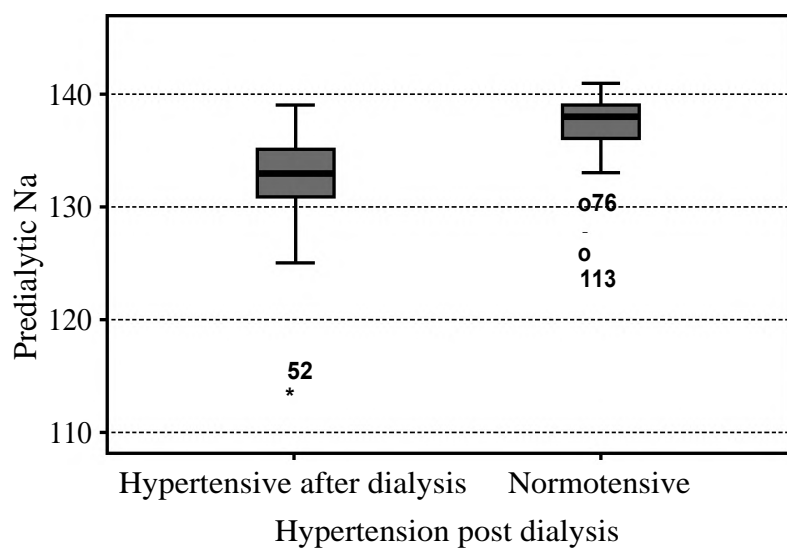

Fig. (3): Boxplot shows the difference in predialytic plasma $\mathrm{Na}$ in the two groups.

Table (3): Comparing pre-dialytic $\mathrm{Na}$ and $\mathrm{Na}$ gradient among the two groups.

\begin{tabular}{llll}
\hline & \multicolumn{3}{c}{ Case group Control group } \\
$p$-value \\
\hline Predialytic plasma Na & $132.66 \pm 3.87$ & $137 \pm 2.46$ & .000 \\
Na gradient & $7.33 \pm 3.9$ & $2.7100 \pm 2.4$ & .000 \\
\hline
\end{tabular}

\section{Clinical signs volume overload in each group:}

In the case group; the percentage of patients who had clinical signs volume overload (as lower limb edema and raised Jugular Venous Pressure (JVP)) was $70.0 \%$ which much more than the control group 10\% as shown in Fig. (4). The difference between the two groups according to Chi 2 test was statistically significant with $p$-value 0.000 .

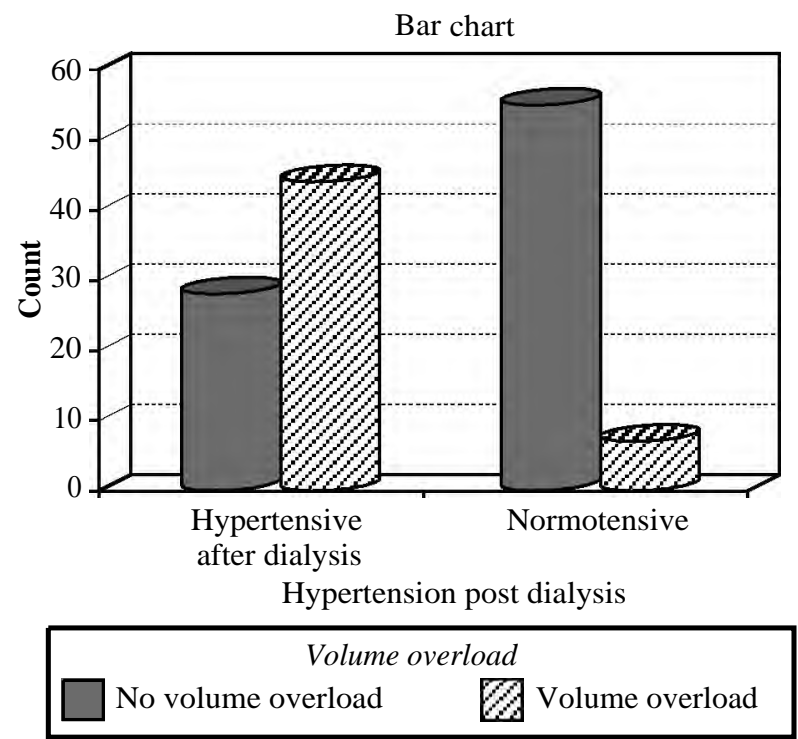

Fig. (4): Number of patients who had clinical signs volume overload in each group. 


\section{Antihypertensive drug intake:}

In the case group; 44 patients $(73.3 \%)$ on antihypertensive treatments which was much more than control group (34 patients $(56.7 \%)$. The difference between the two groups according to $\mathrm{Chi}^{2}$ test was statistically significant with $p$-value 0.042 .

In case group, the most common drugs received by the patients were Calcium Channel Blocker (CCB) (55\%) followed by bisoprolol (30\%). In control group, the most common drugs received by the patients were CCB (43\%) followed by the ARBs (21.7\%).

Table (4): Count and percentages of patients on antihypertensive treatment in each group.

\begin{tabular}{llll}
\hline & $\begin{array}{c}\text { No antihypertensive } \\
\text { drug }\end{array}$ & $\begin{array}{c}\text { Antihypertensive } \\
\text { drug }\end{array}$ & $\begin{array}{c}p \text { - } \\
\text { value }\end{array}$ \\
\hline Case group: & & & \\
Count & 16 & 44 & 0.042 \\
Percentages & $26.7 \%$ & $73.3 \%$ & \\
Control Group: & & & \\
$\quad$ Count & 26 & 34 & \\
Percentages & $43.3 \%$ & $56.7 \%$ & \\
\hline
\end{tabular}

Table (5): Types and percentages of antihypertensive drugs in all patients and in each group.

\begin{tabular}{|c|c|c|c|}
\hline \multirow{2}{*}{ Drug } & \multirow{2}{*}{$\begin{array}{l}\text { Overall } \\
\text { frequency }\end{array}$} & \multicolumn{2}{|c|}{ Frequency } \\
\hline & & Case & Controls \\
\hline $\mathrm{CCB}$ & $59(49.17 \%)$ & $33(55 \%)$ & $26(43.3 \%)$ \\
\hline ARBs & $27(22.5 \%)$ & $14(23.3 \%)$ & $13(21.7 \%)$ \\
\hline Bisoprolol & $24(20 \%)$ & $18(30 \%)$ & $6(10 \%)$ \\
\hline Other beta-blocker & $9 \quad(7.5 \%)$ & $4 \quad(6.7 \%)$ & $(8.3 \%)$ \\
\hline Alpha methyl dopa & $9 \quad(7.5 \%)$ & $(10 \%)$ & $(5 \%)$ \\
\hline Diuretics & $8 \quad(6.67 \%)$ & $(11.7 \%)$ & $(1.7 \%)$ \\
\hline ACEIs & $5 \quad(4.17 \%)$ & $5 \quad(8.3 \%)$ & $(0 \%)$ \\
\hline Alpha-blocker & $1 \quad(0.8 \%)$ & $1 \quad(1.7 \%)$ & $0 \quad(0 \%)$ \\
\hline
\end{tabular}

\section{Number of antihypertensive drugs:}

The number of antihypertensive drugs received by the patients with IDH was more than that received by patients without IDH. This was statistically significant according to independent-samples Mann-Whitney test (non-parametric test as the number of drugs is not normally distributed according to Kolmogorov-Smirnov) with $p$-value 0.012 .

Table (6): The median and interquartile range of antihypertensive drugs received by each group.

\begin{tabular}{lcc}
\hline & Median & Interquartile range \\
\hline Patients with IDH & 1.0 & 2.0 \\
Patients without IDH & 1.0 & 1.0 \\
\hline
\end{tabular}

\section{Number of dialysis sessions:}

The percentage of dialysis sessions number was as in Fig. (4), with percentage of 3 sessions per week was $93 \%$. No significance difference between the two groups according to $\mathrm{Chi}^{2}$ test with $p$-value 0.57 .

\section{Correlation:}

Correlation between different quantitative variables is shown in Table (7). From the table, the following data can be concluded:

- There is moderate significant positive correlation between age and Body Mass Index (BMI) with correlation coefficient 0.374 and $p$-value 0.000 .

- There is strong significant negative correlation between predialytic sodium and sodium gradient with correlation coefficient -0.999 and $p$-value 0.000 .

Table (7): Correlation between different quantitative variables.

\begin{tabular}{|c|c|c|c|c|}
\hline & Age & BMI & $\begin{array}{l}\text { Predialytic } \\
\mathrm{Na}\end{array}$ & $\begin{array}{c}\mathrm{Na} \\
\text { gradient }\end{array}$ \\
\hline \multicolumn{5}{|l|}{ Age: } \\
\hline $\begin{array}{l}\text { Correlation } \\
p \text {-value }\end{array}$ & 1 & $\begin{array}{l}.374^{* *} \\
.000\end{array}$ & $\begin{array}{l}-.142- \\
.121\end{array}$ & $\begin{array}{l}.141 \\
.124\end{array}$ \\
\hline \multicolumn{5}{|l|}{$B M I:$} \\
\hline $\begin{array}{l}\text { Correlation } \\
p \text {-value }\end{array}$ & $\begin{array}{l}.374^{* *} \\
.000\end{array}$ & 1 & $\begin{array}{l}.086 \\
.350\end{array}$ & $\begin{array}{l}-.089- \\
.333\end{array}$ \\
\hline $\begin{array}{c}\text { Predialytic Na } \\
\text { Correlation } \\
p \text {-value }\end{array}$ & $\begin{array}{l}-.142- \\
.121\end{array}$ & $\begin{array}{l}.086 \\
.350\end{array}$ & 1 & $\begin{array}{l}-.999-* * \\
.000\end{array}$ \\
\hline $\begin{array}{l}\text { Na gradient: } \\
\text { Correlation } \\
p \text {-value }\end{array}$ & $\begin{array}{l}.141 \\
.124\end{array}$ & $\begin{array}{l}-.089- \\
.333\end{array}$ & $\begin{array}{l}-.999-* * \\
.000\end{array}$ & 1 \\
\hline
\end{tabular}

\section{Discussion}

In our study, the frequency of IDH was $30 \%$ which is high. Prevalence may differ from study to another due to variation in the definition of IDH, increased number of old age patients in the study due (increased arterial stiffness with age) and lastly, some researchers enrolled patients who recently commenced hemodialysis (dry weight not reached). In one recent cohort study, the prevalence of intradialytic hypertension was 21.3 per 100 treatments [8]. The prevalence of persistent intradialytic hypertension was 8 per 100 patients [8]. This latter finding demonstrated that IDH may be a transient phenomenon. Nongnuch et al., did a prospective audit of 531 patients and found a prevalence of $18 \%$ [9]. Another cross-sectional study involving 190 chronic hemodialysis patients in the Western 
Cape province of South Africa found that the prevalence of IDH was $28.4 \%$ [5].

In our study, the frequency of IDH was $30 \%$ which is high. $70 \%$ of patients with IDH had clinical signs volume overload so dry weight of many patients hadn't been reached. This added to high frequency. No long term follow-up of the patients made the study unable to exclude the transient phenomenon. This also added high frequency.

The mechanistic background of intradialytic hypertension is complex and not yet fully understood. In our study, there was largely statistically significant difference in predialytic plasma $\mathrm{Na}$ between the IDH patients and control group (132.66 and 137 respectively with $p$-value 0.000 ) and there was largely statistically significant difference in $\mathrm{Na}$ gradient between the IDH patients and control group (7.33 and 2.7 respectively with $p$-value $0.000)$. The IDH patients had lower predialytic plasma and higher $\mathrm{Na}$ gradient compared to the control group. There is strong significant negative correlation between predialytic sodium and sodium gradient with correlation coefficient -0.999 and $p$-value 0.000 . This result is similar to multiple previous studies [10-13]. In HD patients, sodium $(\mathrm{Na}+)$ balance depends on dietary salt intake during the interdialytic period and removal of sodium during HD treatment [11]. $\mathrm{Na}+$ gain during the interdialytic period should be removed during HD treatment so that a neutral $\mathrm{Na}+$ balance can be maintained. In $\mathrm{HD}, \mathrm{Na}$ is removed by convection and diffusion. A dNa higher than the plasma sodium concentration $(\mathrm{pNa}) \rightarrow$ diffusion of $\mathrm{Na}$ from dialysate to the patient $\rightarrow$ positive $\mathrm{Na}+$ balance during HD treatment $\rightarrow$ thirst and increased interdialytic water consumption $\rightarrow$ increased IDWG $\rightarrow$ volume overload which is one of the most important factor contributing to the pathogenesis of IDH [10,12-14] Also, none osmotic accumulation of $\mathrm{Na}$ in subcutaneous space and other organs, increased Na stores may affect inflammatory and cardiac fibrotic process via vascular endothelial growth factor [15] Also $\mathrm{Na}$ deposition in arterial smooth muscle may lead to increased vascular stiffness [15] which in turn lead to increased peripheral vascular resistance and blood pressure. Multiple studies have demonstrated that each HD patient has a unique remarkably stable osmolar 'set point' for $\mathrm{pNa}$ [16]. The presence of a stable set point for $\mathrm{pNa}$ has beneficial implications to the $\mathrm{Na}$ and body fluid control and allows the calculation of the sodium gradient $(\mathrm{NaG})$ [17]. Therefore, the use of a fixed $\mathrm{dNa}$ for all HD patients can lead to increased sodium gradient a positive $\mathrm{Na}+$ balance in some hemodialysis patients, which highlights the benefit from $\mathrm{dNa}$ individualization to maintain neutral $\mathrm{Na}+$ balance [16]

Agarwal et al., reported that intradialytic hypertension may be a sign of over hydration and achieving dry weight may lead to a normal decrease in BP during hemodialysis session and achievement of a more normal interdialytic ambulatory BP [18] Another study reported Similar findings using Bioimpedance Spectroscopy (BIS) measurements, where it was found that the ECW: TBW ratio before and after hemodialysis session was greater in those with IDH when compared with those who experienced intradialytic hypotension [9] . Cirit et al., evaluated seven hypertensive chronic hemodialysis patients who had marked cardiac dilatation and whose blood pressure rose with further ultrafiltration [19]. The patients were treated with repeated good ultrafiltration to decrease their dry weight, and cardiac function was monitored. Complete or partial normalization of blood pressure (without the need for antihypertensive agents) was achieved for all patients. Echocardiographic parameters, also improved. The authors explained that fluid overload $\rightarrow$ cardiac dilatation. Removal of excess fluid by ultrafiltration $\rightarrow$ improvement of cardiac output and RAAS activation $\rightarrow \uparrow$ BP. In our study, the percentage of patients with IDH who had clinical signs of volume overload, like lower limb edema, raised JVP and puffiness, was $70.0 \%$ while the percentage of control patients who had clinical signs of volume overload was $10 \%$. This was statistically significant compared to control group. But more accurate methods are needed to evaluate the volume status of the patients like bioimpedance spectroscopy.

In a previous study, participants with intradialytic hypertension were older, they received a greater number of antihypertensive drugs [7]. Eftimovska-Otovic et al., found that; older age, lower body mass index, borderline hyponatremia, higher sodium gradient were the clinical characteristics of patients with intradialytic hypertension [12]. In our study, the patients with IDH were older, but there was no statistically significant difference compared to the control group. They had lower body mass index, but there was no statistically significant difference compared to the control group. The patients with IDH, 44 patients $(73.3 \%)$ on antihypertensive treatments which was much more than control group (34 patients $(56.7 \%)$. This was statistically significant according to Chi ${ }^{2}$ test with $p$-value 0.042 . The number of antihypertensive drugs received by the patients with IDH was more than that received by patients without IDH. This was statistically significant difference according 
to independent-samples Mann-Whitney with $p$ value 0.012 . The greater need for antihypertensive drugs is logic as they did not reach dry weight.

\section{Conclusion:}

The frequency intradialytic hypertension in our center was $30 \%$. Intradialytic hypertension is strongly associated with increased sodium gradient.

\section{Recommendations:}

- Regular checkup of serum sodium to individualize dialysate sodium as possible.

- Dry-weight reduction must be considered an initial approach in IDH patient.

\section{References}

1- DINESH K., KUNAPARAJU S., CAPE K., FLYTHE J.E., FELDMAN H.I. and BRUNELLI S.M.: A model of systolic blood pressure during the course of dialysis and clinical factors associated with various blood pressure behaviors. American Journal of Kidney Diseases, 58 (5): 794-803, 2011.

2- VAN BUREN P.N. and INRIG J.K.: Mechanisms and treatment of intradialytic hypertension. Blood purification, 41 (1-3): 188-93, 2016.

3- INRIG J.K., PATEL U.D., TOTO R.D. and SZCZECH L.A.: Association of blood pressure increases during hemodialysis with 2-year mortality in incident hemodialysis patients: A secondary analysis of the Dialysis Morbidity and Mortality Wave 2 Study. American Journal of Kidney Diseases, 54 (5): 881-90, 2009.

4- DORHOUT M.E.: Rise in blood pressure during hemodialysis-ultrafiltration: A" paradoxical" phenomenon? The International Journal of Artificial Organs, 19 (10): 569, 1996.

5- SEBASTIAN S., FILMALTER C., HARVEY J. and CHOTHIA M.Y.: Intradialytic hypertension during chronic haemodialysis and subclinical fluid overload assessed by bioimpedance spectroscopy. Clinical Kidney Journal, 9 (4): 636-43, 2016.

6- PARK J., RHEE C.M., SIM J.J., KIM Y.L., RICKS J., STREJA E., et al.: A comparative effectiveness research study of the change in blood pressure during hemodialysis treatment and survival. Kidney International, 84 (4): 795 802, 2013.

7- INRIG J.K.: Intradialytic hypertension: A less-recognized cardiovascular complication of hemodialysis. American Journal of Kidney Diseases, 55 (3): 580-9, 2010.
8- VAN BUREN P.N., KIM C., TOTO R.D. and INRIG J.K.: The prevalence of persistent intradialytic hypertension in a hemodialysis population with extended follow-up. The International Journal of Artificial Organs, 35 (12): 1031-8, 2012.

9- NONGNUCH A., CAMPBELL N., STERN E., ELKATEB S., FUENTES L. and DAVENPORT A.: Increased postdialysis systolic blood pressure is associated with extracellular overhydration in hemodialysis outpatients. Kidney International, 87 (2): 452-7, 2015.

10- MOVILLI E., CAMERINI C., GAGGIA P., ZUBANI R., FELLER P., POIATTI P., et al.: Role of dialysis sodium gradient on intradialytic hypertension: An observational study. American Journal of Nephrology, 38 (5): 413-9, 2013.

11-SANTOS S.F. and PEIXOTO A.J.: editors. Sodium balance in maintenance hemodialysis. Seminars in dialysis, Wiley Online Library, 2010.

12- EFTIMOVSKA-OTOVIC N., GROZDANOVSKI R., TANEVA B. and STOJCEVA-TANEVA O.: Clinical characteristics of patients with intradialytic hypertension. prilozi, 36 (2): 187-93, 2015.

13- HECKING M., KARABOYAS A., SARAN R., SEN A. INABA M., RAYNER H., et al.: Dialysate sodium concentration and the association with interdialytic weight gain, hospitalization, and mortality. Clinical Journal of the American Society of Nephrology, 7 (1): 92-100, 2012.

14- MUNOZ MENDOZA J., SUN S., CHERTOW G.M., MORAN J., DOSS S. and SCHILLER B.: Dialysate sodium and sodium gradient in maintenance hemodialysis: A neglected sodium restriction approach? Nephrology Dialysis Transplantation, 26 (4): 1281-7, 2011.

15- ZAHED N.S., GHAROOI O., GACHKAR L. and NIKBAKHT H.: The evaluation of relationship between blood pressure and dialysate $\mathrm{Na}$ concentration in chronic hemodialysis patients. Journal of Renal Injury Prevention, 5 (3): 118, 2016.

16- LOMONTE C. and BASILE C.: Do not forget to individualize dialysate sodium prescription. Oxford University Press, 2011.

17-PEIXOTO A.J., GOWDA N., PARIKH C.R. and SANTOS S.F.: Long-term stability of serum sodium in hemodialysis patients. Blood purification, 29 (3): 264-7, 2010.

18-AGARWAL R. and LIGHT R.P.: Intradialytic hypertension is a marker of volume excess. Nephrology Dialysis Transplantation, 25 (10): 3355-61, 2010.

19- CIRIT M., AKCICEK F., TERZIOGLU E., SOYDAŞ C., OK E., ÖZBAŞLI Ç., et al.: 'Paradoxical'rise in blood pressure during ultrafiltration in dialysis patients. Nephrology Dialysis Transplantation, 10 (8): 1417-20, 1995. 


\section{دورزيادة التدرج فى الصوديوم بين سائل الغسيل الكلوى ودم المريض الفي إنى

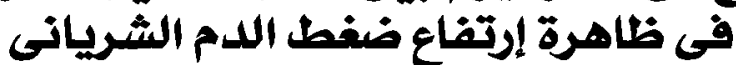

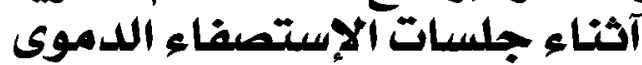

تم إجراء دراسة مقطعية على · . مريض من مرضى الفشل الكلوى بوحدة غسيل الكلى بمستشفيات جامعة آسيوط لتصديد مدىى إنتشار

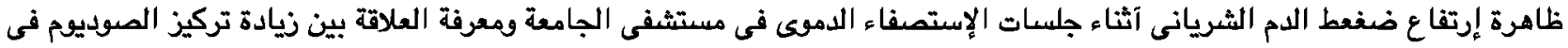

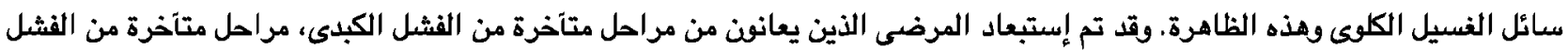

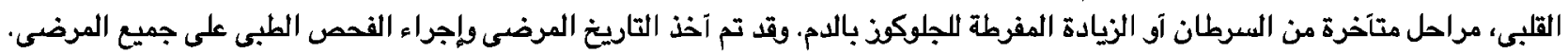

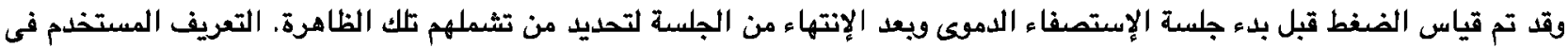

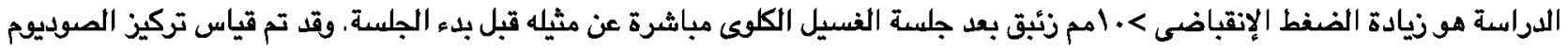

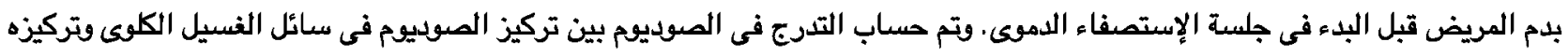

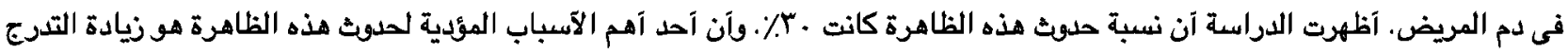

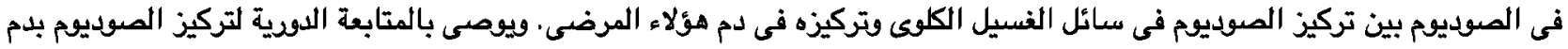

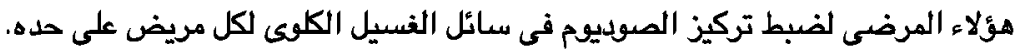

